\title{
SOLUBILIZACION DE ROCA FOSFORICA CAROLINA DEL NORTE CON CEPAS DE Aspergillus niger AISLADAS DESDE UN SUELO TRUMAO
}

(Solubilization of North Caroline phosphoric rock with strains of Aspergillus niger isolated from trumao soil)

\author{
Eduardo Valenzuela $F^{1}$., Sylvia Barrera $P^{1}$. \& Dante Pinochet $T^{2}$. \\ ${ }^{1}$ Instituto de Microbiología, Facultad de Ciencias, \\ Universidad Austral de Chile. Casilla 167. Valdivia - Chile. \\ ${ }^{2}$ Instituto de Ingeniería Agraria y suelo, Facultad de Ciencias Agrarias, \\ Universidad Austral de Chile. Casilla 567. Valdivia - Chile.
}

Palabras clave: Aspergillus niger, roca fosfórica, solubilización.

Key words: Aspergillus niger, phosphoric rock, solubilization.

\section{RESUMEN}

Se estudió en distintos períodos de tiempo de solubilización de roca fosfórica Carolina del Norte, (0 60 d. incubación), adicionada a caldo malta al 2\%, inoculado con 2 cepas nativas de Aspergillus niger I y II, aisladas desde suelo trumao de la X Región y una cepa control de A. niger CBS. Finalizados los períodos de incubación se filtró el medio de cultivo y se determinó la concentración de fósforo solubilizado por el método de Murphy y Riley, el pH y el peso seco de los micelios fúngicos. Los datos obtenidos se sometieron a un análisis de varianza y la prueba de Tukey.

Las cepas A. niger I, II y la cepa control solubilizaron fósforo significativamente. El máximo de solubilización (10153.60 mg/L) se determinó a los 45 días de incubación en el tratamiento con A. niger II. En los medios de cultivo inoculados con estas mismas cepas se determinaron valores bajos de $\mathrm{pH}$ que fluctuaron entre 3.6 y 4.1. A los 60 días las cepas de A. niger y el control alcanzaron valores de peso seco micelial que fluctuaron entre 2.01 y $2.18 \mathrm{~g}$.

\section{INTRODUCCION}

El fósforo es un nutriente esencial para el crecimiento de los vegetales y un constituyente fundamental de los sistemas de captación, almacenamiento, transferencia de energía y forma parte de la mayoría de los procesos fisiológicos de los organismos (Havlin et al., 1999). Del contenido total de fósforo del suelo una porción que osci-

\section{ABSTRACT}

The solubilization of North Caroline phosphoric rock was studied at different periods of times (between 0 and 60 days of incubation) by adding malt broth (2\%) and inoculating 2 native strains of Aspergillus niger I and II which were isolated from trumao soils of the $X$ region and a control strain of A. niger CBS. At the end of the incubation period, the culture media was filtered and $\mathrm{pH}$, dry weight of fungal mycelia and the concentration of solubilized phospho-rous were determined by the Murphy and Riley methods. Data obtained were analyzed by using a variance analysis and a Tukey test.

The A. niger I and II strains and the control strain solubilized significantly phosphorous. The maximum solubilization $(10153.60 \mathrm{mg} / \mathrm{L})$ was determi-nated at 45 days of incubation using the treatment with A. niger II . In the culture media inoculated with these same strains low pH values were determined, ranging from 3.6 to 4.1. At 60 days of incubation, A. niger strains I and II and the control strain reached values of mycelial dry weight, ranging from 2.01 to $2.18 \mathrm{~g}$.

la entre 0.03 a $0.3 \mathrm{mg} / \mathrm{L}$ se encuentra en solución, por lo cual este nutriente debe ser reemplazado varias veces desde las fracciones lábiles del suelo para asegurar la óptima nutrición de los vegetales. Cuando un suelo es incapaz de suministrar este elemento debe ser adicionado externamente para cubrir los requerimientos de los vegetales (Dominguez, 1997). 
En los suelos de la zona sur de Chile, parte del fósforo soluble aplicado como fertilizante reacciona adsorbiéndose a las arcillas a otros coloides o precipita como compuesto fosforado insoluble de acuerdo al pH del medio (Pinochet, 1997). En los suelos ácidos precipita como fosfatos de aluminio o fierro (variscita o estrengita), en tanto los fosfatos de calcio tienden a solubilizarse (Tisdale et al., 1993). Por ello, el uso de fertilizantes constituidos por fosfatos de calcio precipitados que solubilizan a $\mathrm{pH}$ ácido, han sido postulados como una alternativa de uso en los suelos ácidos (Wild, 1992; Havlin et al., 1999). Entre los compuestos precipitados comunes de calcio se encuentran las rocas fosfóricas que representan la forma más simple de suministro de fósforo, pues corresponden a fertilizantes naturales usualmente decacálcicos cuya común composición es $\mathrm{Ca}_{10} \mathrm{PO}_{4}$, y su solubilidad es dependiente de los reemplazos de los fosfatos por los carbonatos, floruros e hidróxidos presentes en la composición de la roca. Casi sin excepción, las rocas fosfóricas son minerales fosfatados nativos que contienen poco o nada de fósforo soluble en agua (Campillo, 1990; Sepúlveda et al., 1997) y cantidades variables de fósforo soluble en citrato (Campillo, 1990; Tisdale et al., 1993). La eficiencia de las rocas fosfóricas depende de su solubilidad y para aumentarla se han desarrollado procesos como la acidulación parcial (Lewis et al., 1997; Sepúlveda et al., 1997; Reyes, 1999), reacciones con ácidos orgánicos sintéticos (Sagoe et al., 1998, citados en Goenadi et al., 2000) y/o ácidos orgánicos naturales (Singh y Amberger, 1998, citados en Goenadi et al., 2000) y la disminución del tamaño de las partículas (Babare et al., 1998). Por otra parte, en la década de los 80 se reportaron algunas cepas de hongos capaces de solubilizar roca fosfórica (Tisdale et al., 1993). Entre otros se encuentran: Aspergillus aculeatus, A. awamori, A. candidus, $A$. foetidus, $A$. fumigatus, $A$. japonicus, $A$. niger (Narsian et al., 1993; Singal et al., 1994; Bojinova et al., 1997; Vassilev et al., 1997; Goenadi et al., 2000; Narsian y Patel, 2000; Wahid y Mehana, 2000), Penicillium bilaii, $\boldsymbol{P}$. digitatum, P. fuscum, P. pinophilum (Asea et al., 1988; Wahid y Mehana, 2000; Arora y Gaur, 1979, citados en Whitelaw, 2000) y Trichoderma harzianum (Altomare et al., 1999). En relación a los mecanismos involucrados en la solubilización de fósforo, el más importante estaría dado por la excreción de ácidos orgánicos que ejercerían su acción por disminución de pH (Gadd, 1999; Whitelaw, 2000) o por la quelación de los cationes de calcio, fierro o aluminio a los que está unido el fósforo y la consiguiente transformación a formas solubles en agua. Kpomblekou y Tabatabai (1994), estudiaron el efecto de los ácidos orgánicos en la liberación de fósforo a partir de roca fosfórica y encontraron que esta tendría relación con la estructura química, tipo y posición de los grupos funcionales de los ligandos y de la concentración de los ácidos. Además, al estar el fósforo de la roca fosfórica principalmente asociado al calcio, los ácidos orgánicos que quelen efectivamente este elemento aumentarían la liberación de fósforo. También se ha reportado solubilización de fósforo inorgánico en ausencia de ácidos orgánicos, como resultado de la acidificación del medio de cultivo (Asea et al., 1988; Illmer y Schinner, 1995). Según Illmer y Schinner (1995), esto se debería a la excreción de protones desde el citoplasma a la superficie externa de la célula.

En estudios de solubilización de varias fuentes de fósforo realizados con hongos en cultivos líquidos, se han identificado los ácidos orgánicos producidos. Singal et al. (1994), detectaron ácido oxálico en cultivos de $\boldsymbol{A}$. foetidus y A. japonicus; Illmer et al. (1995) y Goenadi et al. (2000), ácido cítrico, oxálico, glucónico y málico en cultivos de $\boldsymbol{A}$. niger; Altomare et al. (1999), ácido cítrico, málico, succínico, láctico y fumárico en cultivos de T. harzianum; Whitelaw et al. (1999) ácido glucónico en cultivos de $\boldsymbol{P}$. radicum.

Según Whitelaw (2000) los hongos solubilizadores de fuentes fosforadas inorgánicas insolubles, pueden ser inoculados en cultivos vegetales promoviendo el crecimiento e incrementando el fósforo captado por las plantas. Wahid y Mehana (2000), inocularon A. niger, $\boldsymbol{A}$. fumigatus y $\boldsymbol{P}$. pinophilum en suelos deficientes en fósforo tratados con roca fosfórica, determinando un marcado incremento del fósforo disponible y una mayor eficiencia de los cultivos. Por último, Kpomblekou y Tabatabai (1994), señalan que en la manufactura de fertilizantes fosforados como el superfosfato, los costos de producción aumentan constantemente y se generan problemas medioambientales, particularmente porque se usan ácidos para tratar la roca fosfórica, por lo cual es necesario investigar procesos alternativos. Goenadi et al. (2000) plantean la alternativa de usar hongos solubilizadores de fósforo para tales fines.

En el presente estudio se planteo evaluar la capacidad de dos cepas nativas de $\boldsymbol{A}$. niger aisladas de un suelo trumao de la X Región para solubilizar fósforo a partir de roca fosfórica Carolina del Norte, en un medio de cultivo líquido a diferentes períodos de tiempo en condiciones de laboratorio.

\section{MATERIALES Y METODOS}

I) Ensayo de solubilización de roca fosfórica Carolina del norte. En el ensayo se utilizaron dos cepas de $\boldsymbol{A}$. niger (designadas como I y II) previamente aisladas desde un suelo trumao de la X Región y conservadas en el cepario del Instituto de Microbiología, Facultad de Ciencias Universidad Austral de Chile. Como control se utilizó una cepa de A. niger proveniente del CBS. Las cepas (junto al control) fueron procesadas individualmente y por triplicado. Las cepas previamente fueron cultivadas en agar extracto malta al 2\% y luego con ayuda de un sacabocado estéril se 
extrajeron discos de agar con micelio de $1 \mathrm{~cm}$ de diám. y se inocularon en matraces (cada uno con 3 discos) que contenían, previamente esterilizados en un autoclave $\left(121^{\circ} \mathrm{C}\right.$ por 20 minutos), los medios de cultivos que se indican a continuación: se inocularon por cada cepa y control 18 matraces, cada uno contenía $100 \mathrm{~mL}$ de caldo malta al 2\% más $10 \mathrm{~g}$ de roca fosfórica Carolina del Norte (CM + RF). También se emplearon 36 matraces controles sin inóculo, 18 de ellos contenían $100 \mathrm{~mL}$ de CM + 10 g de RF y los restantes contenían $100 \mathrm{~mL}$ de CM . Además, se incluyó una caracterización inicial (día cero) de CM + RF y de CM antes de su esterilización. Los matraces sembrados y no sembrados con las cepas se incubaron en un agitador orbital a $1500 \mathrm{rpm}, 20^{\circ} \mathrm{C}$ en oscuridad, hasta por 60 días. Para determinar la solubilización de fósforo, el pH del medio de cultivo y el peso seco de los micelios en cada período de incubación ( $0,7,15,30,45$ y 60 días), se retiraron 3 matraces inoculados con cada cepa y 9 matraces control (3 con CM + RF esterilizado e inoculadas con la cepa control, 3 con CM + RF esterilizado y 3 con CM esterilizado).

II) Determinación de fósforo solubilizado, $\mathrm{pH}$ y peso micelial. Finalizados los períodos respectivos de incubación el contenido de cada matraz se filtró individualmente a través de filtros de papel Whatman $\mathrm{n}^{\circ} 5 \mathrm{y}$ del filtrado se recolectaron alícuotas de $10 \mathrm{~mL}$ a las cuales por triplicado se les determinó el fósforo solubilizado mediante el método de Murphy y Riley (1962), leyendo a una longitud de onda de $880 \mathrm{~nm}$ en un espectrofotómetro GBC (UV/ VIS 916) y el pH mediante un pHmetro Zeiss. Lo que quedó retenido en los filtro (micelio fúngico) se utilizó para establecer el incremento de la masa celular a los distintos períodos de incubación. Para lo cual, el micelio se extrajo del filtro de papel y se depositó sobre una gasa lavándose con abundante agua destilada hasta eliminar los restos de roca fosfórica. Posteriormente se eliminó el exceso de agua, el micelio se depositó en placas Petri y se llevó a una estufa de secado a $70{ }^{\circ} \mathrm{C}$ hasta obtener un peso constante (peso seco). Los datos obtenidos de fósforo solubilizado, $\mathrm{pH}$ y peso micelial por triplicado para cada período de tiempo se sometieron a análisis estadístico.

III) Diseño experimental y estadístico. Utilizando un diseño completamente al azar se realizó un experimento de incubación a través del tiempo para estudiar la solubilización de fósforo a partir de roca fosfórica Carolina del Norte (RF) tras la inoculación de las cepas fúngicas en estudio, la variación del peso micelial y el pH del medio de incubación. Se incluyeron controles con y sin inóculo y una caracterización inicial (día cero) del CM con y sin RF previo a su esterilización. Se trabajó por triplicado cada una de las cepas en estudio y controles y se incubaron por 0, 7, 15, 30, 45 y 60 días (resumido en Tabla 1). Los valores obtenidos de los tratamientos, con sus respectivos días de incubación y ordenados en el tiempo fueron analizados por medio del programa estadístico Statgraphics Plus. Se efectuó un análisis de varianza (ANDEVA) y la prueba de Tukey, considerando un 5\% de significancia para detectar si existieron diferencias estadísticamente significativas de los tratamientos en el tiempo y entre tratamientos.

\section{RESULTADOS}

No se aprecian diferencias en la solubilidad de fósforo entre los tratamientos controles $\mathrm{CM}+\mathrm{RF}$ esterilizado y CM esterilizado durante el período de evaluación (p $>0.05)$. Ambos tratamientos, muestran una ligera solubilización del fósforo, el cual parece provenir principalmente del medio de cultivo. Al día 7 de incubación las concentraciones de fósforo soluble aumentaron tanto en $\mathrm{CM}+\mathrm{RF}$ esterilizado (26.09 mg/L) como en el CM esterilizado (38.87 mg/L) en comparación al día 0. Hacia los 15 días la concentración de fósforo soluble para CM + RF esterilizado continuó aumentando ( $34.25 \mathrm{mg} / \mathrm{L}$ ), en cambio para CM esterilizado disminuyó (35.23 mg/L), igualando las diferencias observadas en el día 7. Al final del experimento (día 60) la concentración de fósforo soluble registrada en $\mathrm{CM}+\mathrm{RF}$ esterilizado (37.50 mg/L) disminuyó con respecto al período de incubación anterior (45 días), lo que no es estadísticamente significativo y para CM esterilizado (35.62 $\mathrm{mg} / \mathrm{L}$ ) se detectó un incremento significativo (Figura 1A).

En lo que respecta al fósforo solubilizado en los medios de cultivo inoculados con las cepas de Aspergillus niger (Figura $1 \mathrm{~B}$ ), todas produjeron una notable solubilización de fósforo proveniente de la roca fosfórica a través del tiempo. Esta solubilización es altamente significativa y superior a todos los tratamientos considerados en este estudio ( $\mathrm{p}<0.05$ ). Se observa que hasta el día 30 hubo un incremento de la solubilización de este elemento, tanto por las cepas en estudio como control, siendo el mayor

Tabla 1 . Diseño experimental

\begin{tabular}{|c|c|c|c|c|c|c|}
\hline \multirow{6}{*}{\begin{tabular}{l} 
Grupo deTratamiento \\
\multicolumn{1}{c}{ Control } \\
$\mathrm{CM}+\mathrm{RF}$ esterilizado $=*$ \\
$\mathrm{CM}+\mathrm{RF}$ sin esterilizar \\
$\mathrm{CM}$ esterilizado \\
$\mathrm{CM}$ sin esterilizar
\end{tabular}} & \multicolumn{6}{|c|}{ DÍAS DE INCUBACIÓN } \\
\hline & & & & & & \\
\hline & 0 & 7 & 15 & 30 & 45 & 60 \\
\hline & 0 & & & & & \\
\hline & 0 & 7 & 15 & 30 & 45 & 60 \\
\hline & 0 & & & & & \\
\hline $\begin{array}{c}\text { Aspergillus niger }+* \\
\text { Ensayo }\end{array}$ & 0 & 7 & 15 & 30 & 45 & 60 \\
\hline Aspergillus niger I + * & 0 & 7 & 15 & 30 & 45 & 60 \\
\hline Aspergillus niger II +* & 0 & 7 & 15 & 30 & 45 & 60 \\
\hline
\end{tabular}

$\mathrm{CM}+\mathrm{RF}=$ caldo malta al $2 \%$ adicionado de roca fosfórica Carolina del Norte $\mathbf{C M}=$ caldo malta al $2 \%$. 
incremento (7989.87 mg/L) detectado en el medio de cultivo inoculado con A. niger II y el menor incremento (7105.47 $\mathrm{mg} / \mathrm{L}$ ) en el medio de cultivo inoculado con A. niger I. Según el análisis estadístico el aumento de fósforo solubilizado detectado en estos medios de cultivo sólo fue significativo a partir de los 15 días de incubación, además, las diferencias antes expuestas de las concentraciones de fósforo solubilizado a los 30 días no son significativas. A los 45 días la concentración de fósforo solubilizado por las cepas A. niger I y II continuó aumentando (8692.00 y $10153.60 \mathrm{mg} / \mathrm{L}$ respectivamente) siendo esta última la que registró el "pick” máximo, en cambio, la cepa control registró una disminución del fósforo solubilizado (7568.80 mg/ $\mathrm{L}$ ), pero este decremento no es estadísticamente significativo. Al final del ensayo (día 60) el fósforo solubilizado determinado en los medios de cultivo inoculados con las

Fósforo solubilizado $\mathrm{mg} / \mathrm{L}$

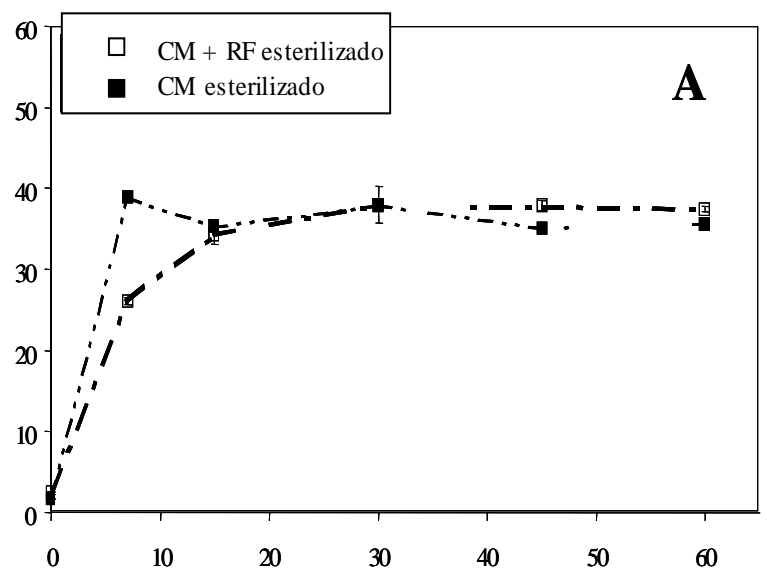

pH del medio de cultivo

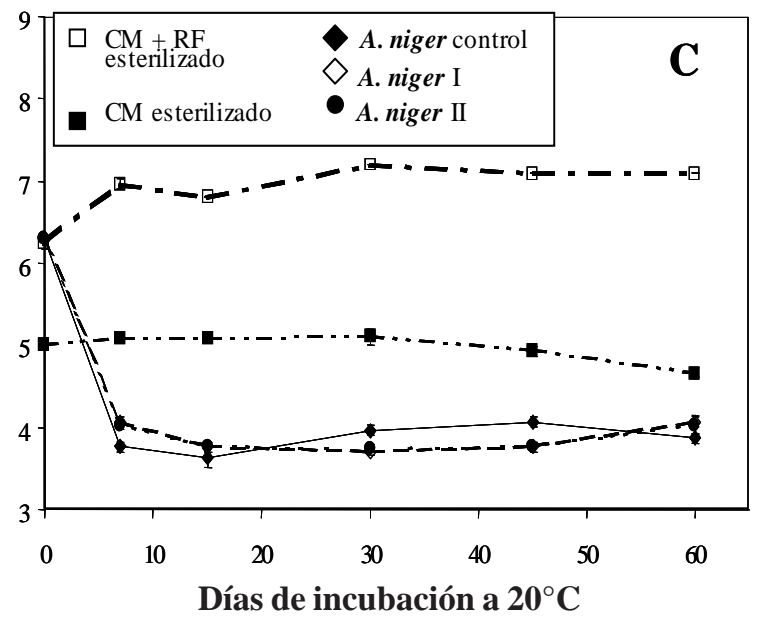

cepas de $\boldsymbol{A}$. niger ensayadas y control disminuyó en comparación al tiempo de incubación anterior, lo que no es estadísticamente significativo para la cepa control. De acuerdo al análisis estadístico ambas cepas estudiadas de A. niger I, II y control conforman un bloque que solubilizó significativamente fósforo, cuyo valor máximo de solubilización se determinó en el tratamiento con A. niger II a los 45 días de incubación.

En lo que respecta al $\mathrm{pH}$ se observa que existió una diferencia debida a la adición de la roca fosfórica al medio de cultivo. Esta diferencia en promedio, a través del tiempo de evaluación es cercana a dos unidades de pH. Se observa, además, que a los 7 días de incubación hubo un aumento del pH en CM + RF esterilizado (7.0) y en CM esterilizado (5.1), desde los valores medidos al tiempo de inicio de la incubación. A los 15 días el pH de CM + RF

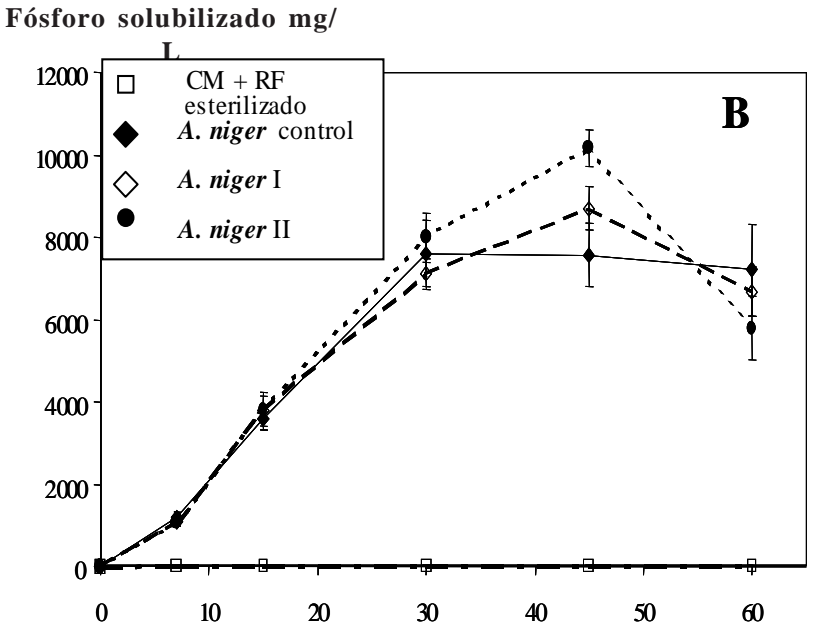

Peso seco del micelio (g)

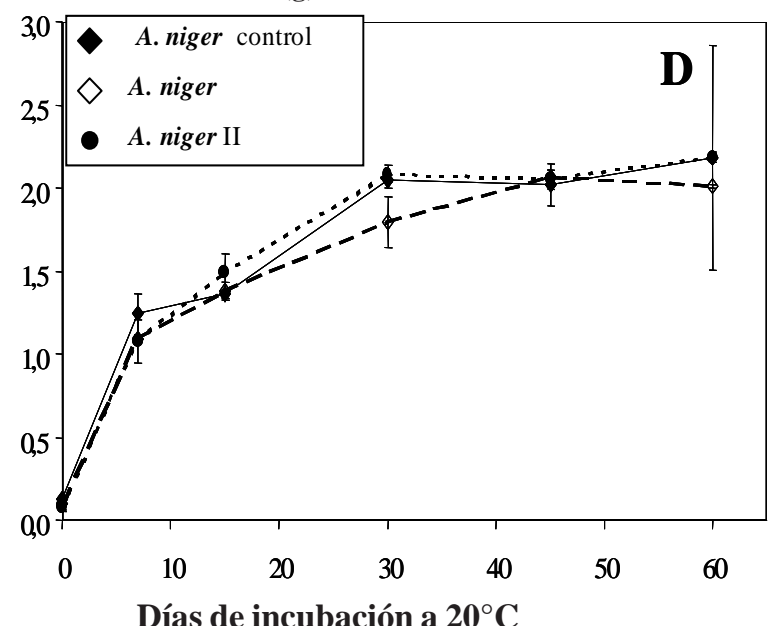

Figura 1. Solubilización de roca fosfórica en el tiempo. A: CM + RF esterilizado y CM esterilizado. B: CM + RF esterilizado y tratado con A. niger I, II y cepa control. C: pH de los medios de cultivos sin inocular e inoculados con las cepas A. niger I, II y control en distintos períodos de incubación (0 a 60 días). D: peso seco micelial de las cepas de A. niger I, II y control en distintos períodos de incubación. Las barras de error indican las desviaciones estándar de las determinaciones en triplicado.

$\mathrm{CM}+\mathrm{RF}=$ caldo malta al $2 \%$ adicionado de roca fosfórica Carolina del Norte. $\mathrm{CM}=$ Caldo malta $2 \%$ 
esterilizado disminuyó (6.8) y para CM esterilizado se mantuvo sin variación. Por último, a los 60 días el pH de CM + RF esterilizado fue 7.1, el que no difiere significativamente con respecto al período de incubación anterior y para CM esterilizado 4.7, siendo significa-tivamente más bajo que el del período de incubación anterior. Por su parte, los cambios producidos en el $\mathrm{pH}$ del medio por las cepas de Aspergillus (Fig. $1 \mathrm{C}$ ), muestran un claro descenso a $\mathrm{pH}$ alrededor de 4.0 que se produjo a través de todo el período de evaluación. A los 7 días de incubación el pH del medio de cultivo inoculado con las cepas $\boldsymbol{A}$. niger I, II y control disminuyó (4.1, 4.0 y 3.8, respectivamente) con respecto al tiempo 0. A los 15 días el $\mathrm{pH}$ de los medios de cultivo continuó disminuyendo (3.8, 3.8 y 3.6 respectivamente). A los 60 días de incubación el $\mathrm{pH}$ aumentó en los tratamientos con A. niger I y II (4.1 y 4.0 respectivamente) y disminuyó en el tratamiento con la cepa control (3.9) en comparación con las determinaciones al período de incubación anterior, además estos valores no difieren significativamente entre ellos. Comparando estadísticamente los resultados de $\mathrm{pH}$ obtenidos de acuerdo al tratamiento y período de incubación se puede señalar que los valores más bajos a lo largo de toda la fase experimental se determinaron en los medios de cultivo inoculados con las cepas $\boldsymbol{A}$. niger I, II y control.

Con respecto al peso seco micelial de $\boldsymbol{A}$. niger I, II y control, éste aumentó gradualmente hasta el día 30 de incubación. Según el análisis estadístico, a los 7 días de incubación se registró un incremento significativo del peso seco micelial para A. niger I, II y control, que se repitió a los 15 días para $\boldsymbol{A}$. niger I y II, pero no para la cepa control; al día 30 aumentó significativamente el peso seco micelial de A. niger I, II y control, cuyo valor máximo se determinó para A. niger II (2.08 g), seguido por la cepa control (2.04 g) y A. niger I (1.80 g), sin embargo, los valores de peso seco micelial registrados para $\boldsymbol{A}$. niger II y la cepa control no difieren significativamente. A los 45 días de incubación, el peso seco micelial aumentó significativamente para $A$. niger I y disminuyó para $\boldsymbol{A}$. niger II y la cepa control, aunque no significativamente. Al día 60 , los valores determinados para las cepas en estudio y control fueron similares, oscilando entre 2.01 y $2.18 \mathrm{~g}$, que no fueron significativamente diferentes entre ellos, ni con respecto al período de incubación anterior. De acuerdo al análisis estadístico, a los 60 días las cepas de $\boldsymbol{A}$. niger y control alcanzaron los valores más altos de peso seco micelial (Fig. 1 D).

\section{DISCUSION}

Son pocos los estudios de solubilización de roca fosfórica por hongos en cultivo líquido (Altomare et al., 1999; Goenadi et al., 2000; Narsian y Patel, 2000; Wahid y
Mehana, 2000) y en ninguno de ellos se ha utilizado como medio de cultivo caldo malta adicionado de roca fosfórica Carolina del Norte. Además, en la mayoría de la literatura concerniente a la solubilización microbiana de fósforo se reportan estudios con bacterias y hongos micorrízicos (Lapeyrie et al., 1991; Chabot et al., 1993; Toro et al., 1997; Bar-Yosef et al., 1999). Sin embargo, algunos hongos no micorrízicos, especialmente de los generos Aspergillus y Penicillium son bien conocidos por su capacidad de solubilización de fósforo (Illmer y Schinner, 1992). Por su parte, Altomare et al. (1999) reportaron por primera vez una cepa de Trichoderma harzianum, capaz de solubilizar minerales insolubles o poco solubles. Recientemente Vassileva et al. (2000) han realizado estudios de solubilización con Yarrowia lipolytica, con potencial aplicación de células libres y encapsuladas para obtener ácido cítrico y solubilizar roca fosfórica.

En la presente investigación, a los 7, 15, 30, 45 y 60 días de incubación, las cepas de Aspergillus niger I, II y control solubilizaron fósforo significativamente (Fig. 1 B), disminuyeron también significativamente el pH de los medios de cultivo (Fig. 1 C), y aumentaron significativamente su peso seco micelial (Fig. 1 D). Con respecto a las investigaciones que utilizaron cepas de Aspergillus en estudios de solubilización, Bojinova et al. (1997), estudiaron la bioconversión de fosfato de roca utilizando diferentes cepas de $\boldsymbol{A}$. niger y concluyeron que el tiempo de incubación, el tipo de cepa y el medio nutritivo son factores que influirían significativamente en este proceso. En el presente estudio A. niger I, II y control, si bien es cierto mostraron diferencias estadísticamente significativas en la concentración de fósforo solubilizado, ellas sólo se manifestaron a los 45 días de incubación, momento que coincidió con los valores máximos de fósforo solubilizado alcanzado por $\boldsymbol{A}$. niger II, seguida por $\boldsymbol{A}$. niger I. En las condiciones del estudio se requirió un período de incubación bastante prolongado para obtener los niveles más altos de solubilización de fósforo en los medios de cultivo tratados con $\boldsymbol{A}$. niger I y II, si bien estos resultados en lo que concierne al tiempo de incubación según Goenadi et al. (2000), serían poco prácticos y restringirían su aplicación a escala industrial. La cantidad de fósforo solubilizado por estas cepas en estudio sobrepasa con creces el promedio descrito en la literatura consultada, lo que amerita su potencial aplicación. La tendencia a reducir la solubilización a los 60 días de incubación fue significativa para $A$. niger I y II, pero no para la cepa control. Esta disminución se puede atribuir según Narsian et al. (1995), citados en Goenadi et al.(2000), a la disponibilidad de formas solubles de fósforo que tendrían un efecto inhibitorio. Según Illmer y Schinner (1992), otra posible explicación estaría dada por la formación de compuestos órgano-fosforado inducidos por metabolitos orgánicos liberados, los que volverían a 
disminuir la cantidad de fósforo disponible. Por último, Vassilev et al. (1995), citados en Whitelaw et al. (1999), sugirieron que la disminución del fósforo observada en la solubilización de roca fosfórica por $\boldsymbol{A}$. niger, probablemente se debería a la utilización del ácido cítrico en condiciones de carencia de nutrientes por parte del hongo. En otros estudios Goenadi et al. (2000), trabajaron con A. niger en la solubilización de roca fosfórica, evaluaron la respuesta a la inoculación de la biomasa fúngica, del líquido sobrenadante de los cultivos y el uso de este último reemplazando al $\mathrm{H}_{2} \mathrm{SO}_{4}$ en la producción de superfosfato. El desarrollo de la biomasa fúngica necesitó un período de incubación considerablemente largo para incrementar el fósforo soluble. Este fenómeno lo atribuyeron al período necesario para que los hongos crezcan y produzcan una cantidad suficiente de ácidos orgánicos que solubilicen el fósforo. La reacción del líquido sobrenadante con la roca fosfórica tuvo mejores resultados y se podría usar en reemplazo del $\mathrm{H}_{2} \mathrm{SO}_{4}$ en la producción de fertilizante para obtener un producto que no dañe el medioambiente. Por su parte, Narsian y Patel (2000), compararon la eficiencia relativa de Aspergillus aculeatus en la solubilización de diferentes tipos de roca fosfórica y encontraron que este proceso dependía del tipo de roca fosfórica y organismos utilizados, además de la naturaleza y cantidad de ácidos orgánicos secretados al medio. Sin embargo, ellos establecieron que se requieren más trabajos en relación a la naturaleza de las rocas fosfóricas y su interacción con microorganismos solubilizadores de fósforo.

En lo que respecta al pH, Whitelaw (2000), realizó una prolija revisión bibliográfica sobre hongos solubilizadores de fósforo y encontró que en la mayoría de los casos el principal mecanismo de solubilización fue la acidificación. Niveles altos de solubilización de fósforo a menudo están asociados a pH bajo del medio de cultivo, a la inversa, una baja solubilización de fósforo a menudo está asociada a un pH alto. Sin embargo, en algunos casos se detectó una alta solubilización de fósforo en el filtrado de medios de cultivo con un $\mathrm{pH}$ relativamente alto. Bardiya y Gaur (1974), citados en Whitelaw (2000), reportaron dos hongos que produjeron una disminución de $\mathrm{pH}$ en casi los mismos valores (Aspergillus awamori cepa $18 \mathrm{~F}$ y un hongo no identificado denominado $21 \mathrm{~F}$ con pH 3.4 y 3.3 respectivamente), mientras que la cantidad de fósforo solubilizado de roca fosfórica fue completamente diferente (116 y 48 mg/L respectivamente), lo que indicaría que la solubilización de fósforo por hongos no sólo dependería del pH del medio de cultivo, sino también de otros factores como el tipo de ácido orgánico excretado. A este respecto, Kpomblekou y Tabatabai (1994), observaron que los ácidos alifáticos con grupos $\beta$ hidroxil y $\alpha$ carboxil son más efectivos que otros ácidos alifáticos o aromáticos en la liberación de fósforo a partir de roca fosfórica. Algunos investigadores han reportado que los ácidos orgánicos son capaces de solubilizar más fósforo que los ácidos inorgánicos al mismo $\mathrm{pH}$, cuya diferencia estaría dada por la quelación. Cunningham y Kuiack (1992), informaron que en presencia de citrato a pH 4.5 la solubilización abiótica de $\mathrm{CaHPO}_{4}$ fue mayor si se compara con la de un ácido inorgánico al mismo $\mathrm{pH}$, lo que indicaría probablemente la quelación por el ácido cítrico. La acidificación artificial del medio de cultivo con $\mathrm{HCl}$ también solubilizó menos fósforo a partir de $\mathrm{CaHPO}_{4}$ insolubles que el solubilizado por Penicillium sp. y Pseudomonas sp. (Illmer y Schinner, 1992). Por su parte, Whitelaw et al. (1999), reportaron que la inoculación de ácido glucónico o de Pencillium radicum fue capaz de solubilizar más fósforo a partir de fosfatos de aluminio amorfos que el $\mathrm{HCl}$ al mismo $\mathrm{pH}$.

En la presente investigación la solubilización de roca fosfórica Carolina del Norte registrada en los medios de cultivo tratados con $\boldsymbol{A}$. niger I, II y control siempre estuvo asociada con valores de $\mathrm{pH}$ muy bajos. Sin embargo, no se puede establecer una relación clara entre la cantidad de fósforo solubilizado y la baja de $\mathrm{pH}$, lo que coincide con lo indicado por Narsian y Patel (2000). Por su parte, Goenadi et al. (2000), en estudios de solubili-zación de roca fosfórica con $\boldsymbol{A}$. niger, encontraron una estrecha relación entre el pH y la cantidad de fósforo solubilizado. Detectaron algunos ácidos orgánicos de los cuales citrato y malato son conocidos por solubilizar compuestos fosforados relativamente insolubles. Illmer et al. (1995), sugirieron que la solubilización de $\mathrm{AlPO}_{4}$ por $\boldsymbol{A}$. niger y Penicillium simplicissimun en un cultivo líquido, probablemente se debió a una acidólisis (disminución de pH), seguido de la formación de complejos por citrato, mientras que para $\mathrm{CaHPO}_{4}$ x $2 \mathrm{H}_{2} \mathrm{O}$ e hidroxiapatita la solubilización fue solo por acidólisis.

En algunos casos se ha reportado la solubilización de fósforo inorgánico en ausencia de la detección de ácidos orgánicos, principalmente como resultado de la acidificación del medio de cultivo (Asea et al., 1988; Illmer y Schinner, 1995). Según Illmer y Schinner (1995), la explicación más probable estaría dada por la excreción de protones del citoplasma a la superficie externa de la célula. Esta hipótesis permitiría asumir que la roca fosfórica puede ser solubilizada directamente en la superficie de la célula. Si esto fuera efectivo, entonces el peso seco de los micelios debería estar estrechamente relacionado con el fósforo solubilizado. De acuerdo a los resultados del presente estudio A. niger I, II y control crecieron y solubilizaron grandes cantidades de fósforo, pero no se estableció si la acidificación del medio de cultivo se debió a la excreción de protones y/o a la producción de ácidos orgánicos.

Por último, en el presente trabajo se determinó que todas las cepas ensayadas de $\boldsymbol{A}$. niger fueron eficientes en la solubilización de la roca fosfórica Carolina del 
Norte, razón por la cual queda abierta la posibilidad de realizar otros estudios complementarios en los que se utilice éstas u otras cepas nativas de $\boldsymbol{A}$. niger y por ejemplo determinar los mecanismos de solubilización involucrados, investigar la solubilización de diferentes tipos de roca fosfórica nativas, o realizar estudios de solubilización en condiciones naturales.

\section{AGRADECIMIENTOS}

Al proyecto DID S-200210 de la Universidad Austral de Chile.

\section{REFERENCIAS}

Altomare, C.; Norvell, W.; Björkman, T. \& Harman, G. (1999).

Nutr. Cycl. Agroecosyst. 47: 227-232

Campillo, R. (1990). Roca fosfórica: Nueva alternativa para fertiliza (Chile). 9: 31-34

Chabot, R.; Antoun, H. \& Cescas, M. (1993). Stimulation de la croissance du maïs et de la laitue romaine par des microorganismes dissolvant le phosphore inorganique. Can. J. Microbiol. 39: 941947

Cunningham, J. \& Kuiack, C. (1992). Production of citric and oxalic acids and solubilization of calcium phosphate by Penicillium bilaii. Appl. Environ. Microbiol. 58: 1451-1458

Dominguez, A. (1997). Tratado de fertilización. Editorial Mundi Prensa. Madrid, España.

Gadd, G. (1999). Fungal production of citric and oxalic acid: importance in metal speciation, physiology and biogeochemical processes. Advances Microbial Physiol. 41: 47-92

Goenadi, D.; Siswanto \& Sugiarto, Y. (2000). Bioactivation of poorly soluble phosphate rocks with a phosphorus-solubilizing fungus. Soil Sci. Soc. Am. J. 64: 927-932

Havlin, J.; Beaton, J.; Tisdale, S. \& Nelson, W. (1999). Soil fertility and fertilizers. An introduction to nutrient management. 6 ed. Prentice Hall. New Jersey, USA.

Illmer, P.\& Schinner,F.(1992). Solubilization of inorganic phosphates by microorganisms isolated from forest soils. Soil Biol. Biochem. 24: 389-395

Illmer, P. \& Schinner, F. (1995). Solubilization of inorganic calcium phosphates-solubilization mechanisms. Soil Biol. Biochem. 27: $257-263$

Illmer, P.; Barbato, A \& Schinner, F. (1995). Solubilization of hardly-soluble $\mathrm{AlPO}_{4}$ with P-solubilizing microorganisms. Soil Biol. Biochem. 27: 265-270

Kpomblekou, K. \& Tabatabai, M. (1994). Effect of organic acids on release of phosphorus from phosphate rocks Soil Sci. 158: 442453
Solubilization of phosphates and micronutrients by the plant-growthpromoting and biocontrol fungus Trichoderma harzianum Rifai 1295-22. Appl. Environ. Microbiol. 65: 2926-2933

Asea, P.; Kucey, R. \& Stewart, J. (1988). Inorganic phosphate solubilization by two Penicillium species in solution culture and soil. Soil Biol. Biochem. 20: 459-464

Babare, A.; Sale, P.; Fleming, N.; Garden, D. \& Johnson, D. (1998). The agronomic effectiveness of reactive phosphate rocks 5. The effect of particle size of a moderately reactive phosphate rock. Austral. J. Exp. Agric. 38: 969-984

Bar-Yosef, B.; Rogers, R.; Wolfram, J. \& Richman, E. (1999). Pseudomonas cepacia-mediated rock phosphate solubilization in kaolinite and montmorillonite suspensions. Soil Sci. Soc. Am. J. 63: 1703-1708

Bojinova, D.; Velkova, R.; Grancharov, I. \& Zhelev, S. (1997). The bioconversion of tunisian phosphorite using Aspergillus niger.

ación de praderas. Investigación y progreso agropecuario Carillanca Lapeyrie, F.; Ranger, J. \& Vairelles, D. (1991). Phosphatesolubilizing activity of ectomycorrhizal fungi in vitro. Can. J. Bot. 69: $342-346$

Lewis, D.; Sale, P. \& Johnson, D. (1997). Agronomic effectiveness of a partially acidulated reactive phosphate rock fertiliser. Austral. J. Exp. Agric. 37: 985-993

Murphy, J. \& Riley, J. (1962). A modified single solution method for the determination of phosphate in natural waters. Analytica Chimica Acta 27: 31-36

Narsian, V.; Thakkar, J. \& Patel, H. (1993). Solubilization of natural rock phosphates and pure insoluble inorganic phosphates by Aspergillus awamori. Indian J. Exp. Biol. 31: 747-749

Narsian, V. \& Patel, H. (2000). Aspergillus aculeatus as a rock phosphate solubilizer. Soil Biol. Biochem. 32: 559-565

Pinochet, D. (1997). Estrategias de fertilización fosforadas en praderas. En: L. Latrille (eds.). Avance en Producción Animal. Serie B20. Publicación Universidad Austral de Chile, Facultad de Ciencias Agrarias, Instituto de Producción Animal. 177-198

Reyes, V. (1999). Evaluación de roca fosfórica parcialmente acidulada en dos tipos de praderas de la Décima Región. Tesis Escuela de Agronomía, Facultad de Ciencias Agrarias, Universidad Austral de Chile.

Sepúlveda, G.; Besoain, E. \& Molina, R. (1997). Rocas fosfóricas chilenas. II. Eficiencia agronómica y su uso como fertilizantes fosfatados en suelos volcánicos. Agric.Téc. (Chile) 57: 225-241

Singal, R.; Gupta, R. \& Saxena, R. (1994). Rock phosphate solubilization under alkaline conditions by Aspergillus japonicus and $\boldsymbol{A}$. foetidus. Folia Microbiol. 39: 33-36

Tisdale, S.; Nelson, W.; Beaton, J. \& Havlin, J. (1993). Soil fertility and fertilizers $5^{a}$ ed. Editorial MacMillan Publishing Company. New York, USA.

Toro, M.; Azcón, R. \& Barea, J. (1997). Improvement of arbuscular mycorrhiza development by inoculation of soil with 
phosphate-solubilizing rhizobacteria to improve rock phosphate biovailability $\left({ }^{32} \mathrm{P}\right)$ and nutrient cycling. Appl. Environ. Microbiol. 63: 4408-4412

Vassilev, N.; Fenice, M.; Federici, F. \& Azcon, R. (1997). Olive mill waste water treatment by inmobilized cells of Aspergillus niger and its enrichment with soluble phosphate. Process Biochem. 32: 617-620

Vassileva, M.; Azcon, R.; Barea, J. \& Vassilev, N. (2000). Rock phosphate solubilization by free and encapsulated cells of Yarrowia lipolytica. Process Biochem. 35: 693-697

Wahid, O. \& Mehana, T. (2000). Impact of phosphate-solubilizing fungi on the yield and phosphorus-uptake by wheat and faba bean plants. Microbiol. Res. 155: 221-227

Whitelaw, M.; Harden, T. \& Helyar, K. (1999). Phosphate solubilisation in solution culture by the soil fungus Penicillium radicum. Soil Biol. Biochem. 31: 655-665

Whitelaw, M. (2000). Growth promotion of plants inoculated with phosphate-solubilizing fungi. Advances Agron. 69: 99-152
Wild, A. (1992). Condiciones del suelo y desarrollo de las plantas según Russell. Editorial Mundi Prensa. Madrid, España. 